\title{
A obrigatoriedade da licitação para empresas estatais exploradoras da atividade econômica sob forma de participação ${ }^{1}$
}

\author{
Sara Dinardi Machado ${ }^{2}$ \\ Prof. Dr. Ruy de Jesus Marçal Carneiro ${ }^{3}$
}

\begin{abstract}
Resumo
Introduz análise acerca da estrutura administrativa, o estudo de seus entes, as empresas estatais. Compara os regimes jurídicos de direito público e de direito privado, e as conseqüências da submissão das empresas estatais exploradoras da atividade econômica a cada um. Analisa o procedimento licitatório, enquanto obrigatório a todos os entes da Administração Pública. Aponta a Emenda Constitucional $n^{\circ}$ 19/98 como deflagradora da discussão. Aponta como resultados: a) a existência de um regime jurídico "híbrido", ao qual se submetem as empresas estatais focadas; b) a relação direta entre a natureza jurídica do regim predominante e a atividade imediatamente realizada pelo ente; c) a incompatibilidade aparente entre o procedimento licitatório, enquanto instituto de direito público, e a atividade econômica realizada pela empresa, de natureza privada; d) a compatibilizacao entre os regimes jurídicos, sem excluir a licitação, mediante a aplicação do instituto da inexigibilidade da licitação; f) a análise da inexigibilidade da licitação aplicada a essas empresas, enquanto situação de "inviabilidade de competição". Conclui que a aplicação do instituto d inexigibilidade da licitação se insere como solução compatibilizadora dos regimes jurídicos de direito privado e de direito público, bem como harmonizadora do conflito entre os princípios da eficiência e da moralidade administrativa, permitindo mais ampla concretização do interesse público.
\end{abstract}

Palavras Chave: Administração Pública; Licitação; Empresas estatais exploradoras da atividade econômica.

\section{Introdução}

“Um Estado nasce da necessidade dos homens; ninguém basta a si mesmo, mas todos nós precisamos de muitas coisas" (PLATÃO apud DALLARI, 1995, p. 46), e, dessa forma, originou-se o Estado, como instituição social criada como instrumento para suprir as crescentes e complexas necessidades dos seres humanos, enquanto indivíduos dentro de um contexto mais amplo, que é a sociedade.

1 Este ensaio teve por referência Trabalho de Conclusão de Curso apresentado ao Curso de Direito da Universidade Estadual de Londrina, de autoria da primeira sob a orientação do segundo.

Aluna do 5으 ano de Direito da Universidade Estadual de Londrina.

3 Doutor em Direito do Estado - Direito Constitucional pela PUC-SP. Procurador Jurídico da Universidade Estadual de Londrina e do programa de Mestrado em Direito Universidade de Marília. 
Assim, para satisfazer as necessidades sociais em razão das quais foi gerado, o Estado, em sua evolução histórica, organizou-se de forma a permitir uma melhor e mais eficaz atuação, segmentou-se, então, numa trilogia de funções: legislativa, judiciária e administrativa. Cada qual possui sua característica própria, uma visando a produção de preceitos normativos limitadores dos indivíduos, outra solucionando conflitos de forma imparcial, e a derradeira aplicando de forma concreta as pretensões sociais, mediante comportamentos infralegais, submissos ao controle da função jurisdicional (MELLO, 2004, p. 34). Trata-se da satisfação prática e concreta das necessidades e anseios da sociedade.

A função administrativa, em virtude da amplitude e complexidade das necessidades da sociedade, não pode ser exercida por apenas um órgão, assim, é necessária a criação de uma estrutura, formada por inúmeros órgãos especializados, jungidos por um mesmo objetivo: o bem-comum. Essa é a Administração Pública, enquanto conjunto de órgãos, numa composição hierárquica, no exercício da função administrativa, dotados de prerrogativas e limitações, focados num objeto único, que é o interesse público, e entranhados no regime jurídico administrativo.

\section{Empresas estatais. Conflito público/privado}

O regime jurídico administrativo pressupõe um conjunto de normas, regras e princípios que regem toda a atuação da Administração Pública, em especial, no exercício da função administrativa. Trata-se de regime jurídico de direito público, assim, concluir-se-ia que, toda a estrutura administrativa estaria sob a regência de tal regime jurídico. Entretanto, as necessidades e relações humanas, econômicas e sociais, atingem tamanha complexidade, que, para sana-las torna-se necessária a criação de sujeitos estranhos a tal raciocínio jurídico lógico. São figuras criadas com caracteres de diferentes regimes jurídicos, inclusive antagônicos, quer seja, de direito público e de direito privado.

Nesse parâmetro inserem-se as empresas estatais, enquanto entes da Administração Pública, mesmo que indiretamente, em razão do fenômeno da descentralização, em especial quando exploram a atividade econômica. Observa-se aqui um aparente conflito entre regimes jurídicos opostos: o caráter público, por tratar-se de ente público, e por isso sob a regência dos princípios administrativos (públicos); e o caráter 
privado, relevado por sua atividade intrínseca, a exploração econômica, que, numa sociedade capitalista, como a brasileira, é de titularidade dos particulares.

A discussão doutrinária acerca da peculiaridade de tais entes não é recente, entretanto, em razão das alterações inseridas no Texto Constitucional pela Emenda Constitucional $n^{\circ}$ 19/1998, aos Arts. 37, XXVII, e 173, trouxeram à tona novos debates sobre o tema.

As empresas estatais exploradoras da atividade econômica são segregadas em dois subgrupos: as que exploram tal atividade sob a forma de monopólio, nos termos do Art. 177 da Constituição Federal; e as que a exploram sob forma de competição, ou participação, nos termos do Art. 173 do Texto Constitucional. Merece especial apreço as inseridas na segunda classificação, pois a elas, além de atuar em atividade de caráter eminentemente privado, cabe fazê-lo em condições de igualdade com os particulares, competindo com os mesmos nesse setor cuja titularidade lhes compete.

Tais empresas podem ter sua atividade segregada em dois subgrupos: as atividadesmeio, e as atividades-fim. O primeiro grupo caracteriza-se pela não vinculação ao cunho econômico, o qual é objeto da própria atuação dos mesmos. Assim, são consideradas atividades-meio aquelas que não demandam a desenvoltura e agilidade exigidas pela atividade econômica competitiva, sendo aquelas que servem apenas de meio para a consecução de tal fim mercantil (JUSTEN FILHO, 2004, p. 20). Um exemplo de atividade-meio seria a construção de um prédio para uma sociedade de economia mista com tais características. O segundo grupo é caracterizado pela vinculação direta com a finalidade imediata da estatal, que é a atividade econômica. São, então, procedimentos usuais do mercado em que a estatal atua, indispensáveis ao desempenho de suas atividades corriqueiras, de cunho econômico, a serem realizadas em igualdade de condições com os demais agentes econômicos.

É evidente que, uma vez o Estado atuante numa atividade sobre a qual não the resta titularidade, mas sim ao particular, deve, com este, explorá-la em condições de absoluta igualdade, e, para tal, não pode dispor das mesmas prerrogativas usufruídas e necessárias ao exercício das funções de natureza pública. Conclui-se, então, que o ente público ao encontrar-se em situação de tal peculiaridade, deve atuar sob as mesmas normas e princípios, com as prerrogativas e limitações de que dispõem os entes privados, reais 
titulares da atividade econômica, ou seja, deveriam as empresas estatais exploradoras da atividade econômica serem regidas pelo regime jurídico de direito privado.

Ainda, fundamenta-se o aspecto privado de tais entes públicos nas alterações inseridas pela Emenda Constitucional n 18/98 que, alterou os Arts.37 e 173 da Constituição Federal de modo a permitir a compreensão de uma diferenciação privatística das empresas estatais exploradoras da atividade econômica, em especial, sob forma de participação. Tal entendimento tanto é passível de consecução que, a nova redação do $\S 1^{\circ}$, I, do Art. 173 , prevê o estabelecimento legal de um estatuto jurídico para tais entes, sujeito ao regime jurídico próprio das empresas privadas.

Entretanto, não podem ser observados os aspectos meramente privados de tais entes, pois, uma vez inseridos na estrutura administrativa, enquanto órgãos da Administração Pública indireta, estão embuídos no objetivo que envolve todos os entes públicos, ou mesmo o Estado em geral, que é o bem-comum, positivado no interesse público. Assim, tais entes, embora exerçam atividade de cunho eminentemente privado, a atividade econômica, o fazem perseguindo tal finalidade única da Administração Pública, pois dessa continuam sendo parte.

Ainda, uma vez Administração Pública, possuem capital parcial ou totalmente público, sociedades de economia mista e empresas públicas respectivamente. Tal fato evidencia ainda mais o caráter público de tais entes, o que permite afirmar que são passíveis de regência pelo regime jurídico de direito público.

\section{Regime jurídico "híbrido"}

Diante do antagonismo citado, resta a submissão, não a um dos regimes jurídicos expostos, e sim a ambos, sendo tais entes regidos por institutos de direito público e de direito privado, gerando-se, assim, um regime jurídico misto, entitulado "híbrido" (DI PIETRO, 2004, p. 385), adequado às opostas características de tais empresas estatais.

Tal regime jurídico é caracterizado pela presença simultânea de institutos jurídicos de direito público, bem como de institutos jurídicos de direito privado, entretanto, há momentos em que se estabelece uma predominância de caracteres de um dos regimes jurídicos em detrimento do outro. Assim, há momentos em que se observa a prevalência do regime jurídico de direito privado, e outros do regime jurídico de direito público. Diante de 
tal ocorrência pode ser estabelecida uma relação direta entre: a atividade imediatamente exercida pelo ente estatal e o regime jurídico predominante neste momento. Assim, nos momentos de exercício de atividadesmeio pelas estatais, pode-se observar a prevalência do regime jurídico de direito público, ao passo que, no exercício imediato de atividades-fim, haverá uma predominância do regime jurídico de direito privado.

Tal relação direta é estabelecida por parâmetros de possibilidade, capacidade de compatibilizar uma atividade sob a regência de determinado regime jurídico. Nesse caso, as atividades-fim, em razão de sua agilidade, e vinculação direta com a atividade econômica, não é capaz de compatibilizar-se com o regime jurídico de direito público, em razão de seu rigorismo e formalismo, então é regida predominantemente pelo regime privado. Por outro lado, as atividades-meio não apresentam obstáculos para se submeterem ao regime jurídico público, dessa forma, nesses momentos será esse o predominante.

\section{Licitação nas empresas estatais exploradoras da atividade econômica sob forma de participação}

Nesse contexto de discussão acerca do regime jurídico ao qual se submetem as empresas estatais enquanto exploradoras da atividade econômica sob forma de participação,cabe inserir debate ainda mais profundo acerca da obrigatoriedade de aplicação do processo licitatório por tais sujeitos.

A licitação é definida como procedimento administrativo, de caráter vinculado, que visa a estabelecer uma disputa entre os administrados interessados em contratar com a Administração Pública, de forma a travar o negócio mais favorável ao interesse público, assim respeitado o princípio da vantajosidade, bem como o da isonomia entre os participantes (JUSTEN FILHO, 2004, p. 12). Tal procedimento administrativo, segundo Art. 37 da Constituição Federal, possui caráter obrigatório a todos os sujeitos da Administração Pública, tanto direta quanto indireta, enquanto antecedente necessário ao estabelecimento de suas relações jurídicas de cunho econômico, ou seja, contratos administrativos.

Nessa dinâmica, o certame licitatório pode ser entendido como expressão clara do regime jurídico de direito público, embuído no interesse público preliminarmente, e nos princípios constantes do regime jurídico administrativo. 
Entretanto, enquanto expressão de caráter público, fundada nos princípios que tal condição Ihe atribui, a licitação adquire aspectos de formalismo, de rigor inclusive exarcebado, o que conota a morosidade do certame como um todo. Esses característicos são decorrência natural da imensa gama de pressupostos a serem preenchidos pelos procedimentos administrativos, de modo a satisfazer e respeitar seu regime jurídico, o administrativo.

Assim, diante dessa visão formal e morosa do procedimento licitatório, gera-se um conflito: a incompatibilidade entre tal procedimento e a exploração da atividade econômica pelas empresas estatais, em especial, sob forma de competição, uma vez que, fazendo parte da Administração Pública, tais entes, segundo o Art. 37 citado, têm o dever de observa-lo, entretanto, sua atividade, a econômica, é dependente de tamanha dinamicidade, que, se aplicado tal certame, com seus aspectos morosos, impediria seu sucesso no setor econômico, enquanto sujeito atuante em iguais condições com os particulares.

Especificando ainda mais a matéria, conclui-se que haverá a incompatibilidade entre a licitação, enquanto expressão do regime jurídico de direito público, e as atividadesfim imediatamente exercidas por tais entes, incompatibilidade esta que não se demonstra quando do exercício das atividades-meio.

\section{Solução legal: inexigibilidade}

Chega-se ao paradigma de conciliar tal antagonismos, permitindo a regência por normas de direito público de atividades de caráter eminentemente privado.

Um meio de legal de conciliar tal conflito é encontrado na própria lei de licitações (lei. 8.666/1993), com a aplicação do instituto da inexigibilidade. Tal instrumento é de caráter excepcional, sendo cabível nas hipóteses em que há a impossibilidade de aplicação do certame licitatório, diante da extrema inviabilidade de competição, aspecto esse essencial ao procedimento aqui ressaltado. Este instituto tem previsão no Art. 25 da lei de licitações, e é utilizado em situações em que a licitação, enquanto instrumento para a consecução do interesse público, passa a feri-lo, tornando-se inútil, ou mesmo desvantajosa sua aplicação. O que ocorre aqui não é a mera exclusão do procedimento licitatório, mas sim a efetivação de um procedimento especial que, com sua devida motivação, permite a maior concretização do interesse público, que seria obstaculizada em razão do certame. 
Inserido tal instituto ao conflito apresentado anteriormente, coaduna sua aplicação às situações em que a aplicação do certame licitatório traria prejuízos ao interesse público, logo, às atividades-fim, enquanto regidas predominantemente pelo regime jurídico de direito privado, em razão de sua incompatibilidade com o procedimento administrativo em questão.

Entretanto, não cabe ao livre entendimento do administrador público a aplicação de tal instituto, há a restrita previsão legal da situação de cabimento, quando da impossibilidade de solução diversa, chamada de discricionariedade técnica (JUSTEN FILHO, 2004, p. 21), pela qual o administrador identifica a hipótese concreta de inviabilidade de competição, apontando tal procedimento como o único cabível. Além desse cabimento restrito, deve-se observar o Art. 26 da lei de licitações, que condiciona a eficácia do procedimento à devida motivação, documentada, nos termos de tal dispositivo legal.

\section{Conclusão}

A Emenda Constitucional $n^{\circ} 19 / 98$ trouxe novamente à tona a discussão acerca do regime jurídico das empresas estatais que exploram a atividade econômica sob forma de participação, em razão do conflito existente entre a atividade eminentemente privada por elas exercida, e o aspecto público decorrente da condição de ente inserido na estrutura da Administração Publica.

O Art. 173 da Constituição Federal, teve sua redação alterada de modo a determinar uma futura produção normativa pelo legislador infraconstitucional, estabelecida a incumbência deste criar o estatuto jurídico das empresas estatais aqui tratadas, e, ainda, sob o regime jurídico próprio das empresas privadas.

Entretanto, enquanto não positivado tal contexto jurídico, permanece o citado conflito, cabendo aos juristas encontrar, dentro de um ordenamento jurídico fechado, que é o brasileiro, soluções legais que possibilitem a convivência entre a atividade privada exercida por tais entes, e a finalidade pública na qual os mesmos estão embuídos, uma vez entes da Administração Pública, focados precipuamente no interesse público.

Nesse contexto insere-se o instituto da licitação, enquanto expressão do regime jurídico de direito público, e de aplicação obrigatória conforme ditames constitucionais (Art. 37, Constituição Federal). Discute-se se seria obrigatória, também para tais entes, dotados 
de tamanha peculiaridade, a aplicação estrita e geral de tal procedimento administrativo, e ainda, se a todas as situações em que pretenderem estabelecer relações jurídicas de cunho econômico com terceiros.

Grande relevância tem tal discussão pois, atualmente, mesmo com a privatização de inúmeras estatais, as exploradoras de atividade econômica competidoras no mercado, uma vez inseridos na Administração indireta, gerem imensas massas de capital público, que, se por um lado deve ser controlado pela aplicação de tal certame (moralidade administrativa), por outro lado essa aplicação geraria prejuízos ao próprio erário, o que também fere o interesse público a que estão jungidos.

Uma solução de compatibilização apontada é observada no próprio texto da lei de licitações, em seu Art. 25, é o instituto da inexigibilidade. Por meio dele, é possível afastar o procedimento licitatório moroso, aplicando-se um procedimento especial que permita, além da consecução eficiente da atividade imediata de tais entes público, que é a econômica, o atingimento do interesse público, mediante o controle de atos do administrador, pois se trata de procedimento cuja eficácia depende da devida motivação, respeitada, assim, a moralidade administrativa.

Importante ressaltar que tal solução legal apresenta caráter meramente provisório, pois, uma vez tendo cumprindo o legislador ordinário sua obrigação constitucional expressa, ou seja, editada a lei que cria o estatuto jurídico específico das empresas estatais, será adotada toda uma nova sistemática acerca de seu regime jurídico, princípios e normas norteadoras, e assim, conclui-se que será criado procedimento próprio para as empresas estatais tratadas estabelecerem relações jurídicas de cunho econômico com os particulares, observado o interesse público em sua maior amplitude.

\section{Referências}

DALLARI, Dalmo de Abreu. Elementos de Teoria Geral do Estado. 19. ed. São Paulo: Saraiva, 1995.

DI PIETRO, Maria Sylvia Zanella. Direito Administrativo. 17. ed. São Paulo: Editora Atlas, 2004.

JUSTEN FILHO, Marçal. Comentários à Lei de Licitações e Contratos Administrativos. 10. ed. São Paulo: Editora Dialética, 2004. 
MELLO, Celso Antônio Bandeira de. Curso de Direito Administrativo. 17. ed. São Paulo: Malheiros, 2004. 
